\title{
Public Health Aspects of Human Brucellosis in the Republic of Macedonia
}

\author{
Milka Zdravkovska ${ }^{1}$, Zharko Stojmanovski ${ }^{2 *}$, Vaso Taleski ${ }^{1}$, Svetlana Jovevska ${ }^{1}$, Velo Markovski ${ }^{1}$ \\ ${ }^{1}$ Goce Delchev University, Faculty of Medical Sciences, Shtip, Republic of Macedonia; ${ }^{2}$ Food and Veterinary Agency, \\ Branch Office Kumanovo, Kumanovo, Republic of Macedonia
}

\begin{abstract}
Citation: Zdravkovska M, Stojmanovski Zh, Taleski V, Jovevska S, Markovski V. Public Health Aspects of Human Brucellosis in the Health Aspects of Human Brucellosis in the Republic of Macedonia. OA Maced J Med Sci. $2013 \quad$ Dec 15; 1(1):108-11
http://dx.doi.org/10.3889/oamjms.2013.022 http://dx.doi.org/10.3889/oamjms.2013.022 public health problem.

"Correspondence: Dr. Milka Zdravkovska. Institute of Epidemiology and Biostatistics, Faculty of Medicine, Vodnjanska No 31, Skopje 1000, Republic of Macedonia. Phone: 00389 3114825.

E-Mail: zdravkovska2003@yahoo.com

Received: 18-Sep-2013; Revised: 18-Oct2013; Accepted: 21-Oct-2013; Online first: 30-Oct-2013

Copyright: $\odot 2013$ Zdravkovska M. This is an open-access article distributed under the terms of the Creative Commons Attribution License, which permits unrestricted use, distribution, and reproduction in any medium, provided the original author and source are credited.

Competing Interests: The authors have declared that no competing interests exist.
\end{abstract}

\begin{abstract}
Background: The Republic of Macedonia is an endemic area where brucellosis is a dominant zoonosis with high morbidity and enormous economic loss.

Aim: To determine the incidence rate, prevalence rate and development tendency of infected people with brucellosis in R. Macedonia in the period from 01.01.1999 to 31.12.2009, to register and analyse the epidemiological characteristics of the infected with brucellosis according to gender, age and regional distribution.
\end{abstract}

Materials and methods: The data about the infected people with brucellosis were taken from the register of individual cases as well as monthly and annual reports for infectious diseases prepared by the Institute for Public Health of Republic of Macedonia.

Results: According to the survey the highest number of incidence of human brucellosis in $R$. Macedonia was found in 2008, 23.94/100,000 people, and the lowest number of infected people was in 2009, about 13.99/100,000 people. Human brucellosis has a decreasing tendency.

Conclusion: Human brucellosis remains a public health problem in Republic of Macedonia.

\section{Introduction}

Brucellosis (Malta fever, Mediterranean fever, Crimean fever, Bang's disease) is an acute or chronic infectious disease caused by the bacteria of the genus Brucella [1]. Due to the prevalence in animals and most established morbidity in humans, brucellosis is a major public health problem worldwide [2].

In 1962 (3 cases), 1963 (3 cases), 1968 (1 patient) and in 1979 (1 patient) were registered individual cases of human brucellosis in Macedonia [3]. In epidemic form, at the territory of the Republic of Macedonia, brucellosis in humans was registered for the first time in 1980 with a total of 112 cases, including 104 cases in the municipality of Bitola, 5 cases in Negotino and 3 carriers of this disease in Kavadarci [3].
Brucellosis as an occupational disease has serious public health consequences such as absenteeism, work disability, long rehabilitation and socio-economic implications [4].

Brucellosis is for more than 30 years a serious public health and socio-economic problem in Macedonia [5-7].

Brucellosis in Macedonia in the past 30 years had intensive epidemiological momentum. Several years after the first epidemic appearance in 1980, Macedonia became endemic area for brucellosis. Although in 1992 the number of people infected with brucellosis showed constant decline, brucellosis still remains a serious problem for animals and people in Macedonia. The main reason for this epidemiological development of brucellosis was lack of a sustainable 
strategy and sufficient resources for continued implementation of the planned measures and activities of health and veterinary services [8].

At the national level, the capacity for rapid response to an outbreak of brucellosis or its endemicity is crucial. To achieve this, the national health and veterinary surveillance and rapid response systems should be synchronized and capable of undertaking cooperative action [9].

\section{Materials and Methods}

The study analyzed all carriers registered in the Republic of Macedonia in the period from 01.01.1999 to 31.12.2009.

The data for people suffering from brucellosis were provided from the reports of the individual cases, as well as monthly and annual reports on infectious diseases, prepared by the Department of Epidemiology at the Institute for Public Health of the Republic of Macedonia, upon application by the ten regional Centers for Public Health in the country.

\section{Results}

In the period from 01.01.1999 unti 31.12.2009 a total of 4,167 people with brucellosis, and one deceased were registered in the Republic of Macedonia.

The greatest incidence (morbidity) was registered in 2008 (23.94 per 100,000 inhabitants), and the lowest in 2009 (13.99 per 100,000 inhabitants). Prevalence of periodic test period was 204.5 cases per 100,000 inhabitants (Table 1 ).

Table 1: Incidence, prevalence and morbidity of human brucellosis in Macedonia in the period 1999-2009.

\begin{tabular}{llccc}
\hline Year & $\begin{array}{l}\text { Population } \\
\text { midyear }\end{array}$ & $\begin{array}{l}\text { Number of } \\
\text { infected } \\
\text { people }\end{array}$ & $\begin{array}{l}\text { Incidence rate } \\
/ 100000 \\
\text { inhabitants }\end{array}$ & $\begin{array}{l}\text { Periodic } \\
\text { prevalence } \\
/ 100,000 \\
\text { inhabitants }\end{array}$ \\
\hline 1999 & 2017000 & 460 & 22.81 & \\
2000 & 2026000 & 422 & 20.83 & \\
2001 & 2035000 & 414 & 20.34 & \\
2002 & 2020000 & 405 & 20.05 & \\
2003 & 2027000 & 378 & 18.65 & $204.5 / 100,000$ \\
2004 & 2032000 & 297 & 14.62 & inhabitants \\
2005 & 2037000 & 323 & 15.86 & \\
2006 & 2040000 & 309 & 15.15 & \\
2007 & 2044000 & 381 & 18.64 & \\
2008 & 2047000 & 490 & 23.94 & \\
2009 & 2051000 & 287 & 13.99 & \\
\hline
\end{tabular}

In the test period, the largest percentage of patients with brucellosis registered were at the age of 60 years and over $744(17.85 \%)$, while the lowest percentage of patients was registered in the age group 0 to 9 years, $286(6.86 \%)$. Analysis of rank correlation (Spearman coefficient: $R=0.86$ ) showed that there was a strong association (connection) between age groups and the emergence of the disease, i.e., statistically significantly more brucellosis occurred in people aged $60 \leq$ years $(t=3.721, p=$ 0.0137) (Table 2).
Table 2: Distribution of patients with brucellosis by age groups in the period $1999-2009$.

\begin{tabular}{ccc}
\hline Age groups & Number of cases & $(\%)$ \\
\hline $0-9$ & 286 & 6.86 \\
$10-19$ & 567 & 13.62 \\
$20-29$ & 576 & 13.82 \\
$30-39$ & 707 & 16.97 \\
$40-49$ & 681 & 16.34 \\
$50-59$ & 606 & 14.54 \\
$60 \leq$ & 744 & 17.85 \\
Total & 4167 & 100.00 \\
\hline
\end{tabular}

Registered brucellosis in children aged 0 to 9 years is separately shown in Table 3 , since the frequency of the disease increases with the increasing age (Pearson-t correlation coefficient: $r=0.96$ ).

Table 3: Distribution of infected children of brucellosis aged 0 to 9 years in the period 1999-2009.

\begin{tabular}{ccc}
\hline Age/year & Number of cases & $(\%)$ \\
\hline 0 & 4 & 1.39 \\
1 & 8 & 2.78 \\
2 & 13 & 4.54 \\
3 & 29 & 10.14 \\
4 & 25 & 8.74 \\
5 & 40 & 13.98 \\
6 & 36 & 12.59 \\
$7-9$ & 131 & 45.84 \\
Total & 286 & 100.00 \\
\hline
\end{tabular}

Of the total of 4167 cases of brucellosis in the exanimate period, there were a total of $2,872(69 \%)$ men and 1,295 (31\%) women. Statistically, men predominated significantly over women, for $p=$ 0.00001 (Figure 1).

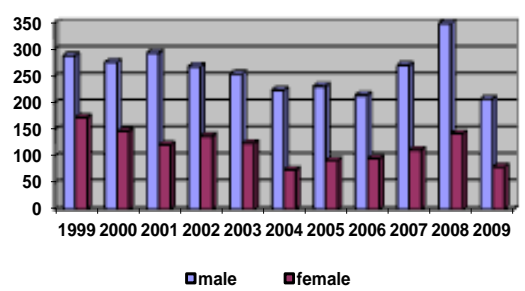

Figure 1: Distribution of people infected with brucellosis by sex for the period 1999-2009 in Republic of Macedonia.

Human brucellosis is a typical seasonal disease, with most cases recorded in spring and summer and a minimum in fall-winter period. Figure 2 shows the distribution of patients by month of registration of the disease, which shows that the number of patients is steadily rising from January to May, reaching its maximum in June and July and then declines.

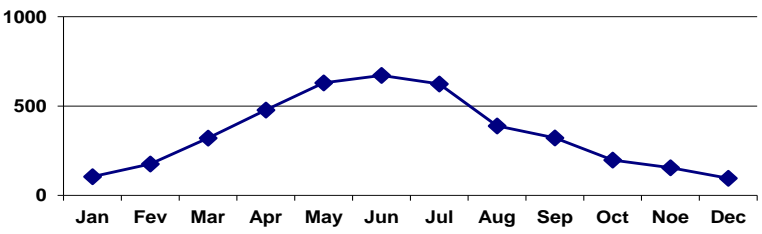

Figure 2: Seasonal distributions of cases of human brucellosis in the period 1999-2009 in Republic of Macedonia.

For the period 1999-2009 a downward trend of this disease in our population- was observed (Figure 3). 


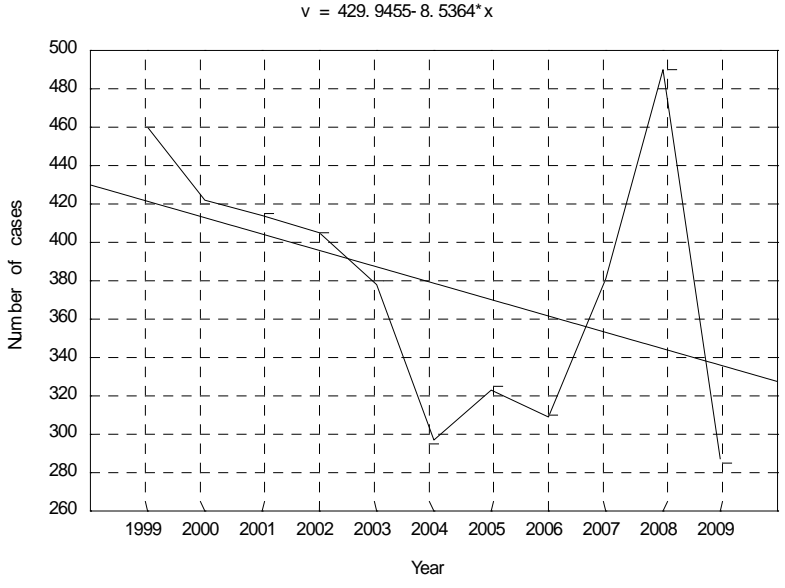

Figure 3: Trend of the disease brucellosis in the population of the Republic of Macedonia in the period 1999-2009.

The distribution of human brucellosis, by regions of the 10 Centers for Public Health, for the examined period showed that-, the biggest number of registered cases was in the region of the Center for Public Health Shtip (Shtip, Radovish and Probishtip) with $26 \%$ of the total number of registered cases in Macedonia, while the lowest number of registered cases in the region of Center for Public Health Kocani (Kochani, Vinica, Berovo and Pehchevo) with $2 \%$ (Figure 4).

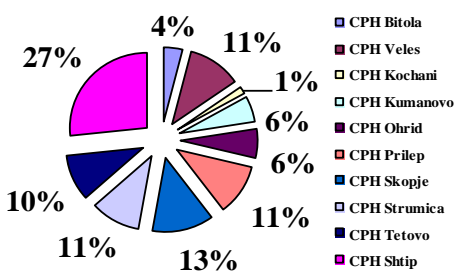

Figure 4: Distribution of human brucellosis through 10 Centers for Public Health (CPH) in Macedonia for the period 1999-2009.

Analysis of variance showed that there were statistically significant differences between regions in terms of the number of people suffering from brucellosis in the analyzed period (Kruskal-Wallis Test: $\mathrm{H}=17.827 ; \mathrm{p}=0.0479$ ).

\section{Discussion}

In the analyzed period the incidence rate of human brucellosis reached its maximum of $23.94 / 100,000$ population in 2008 , while the lowest incidence was registered in 2009, and it was $13.99 / 100,000$ inhabitants. A similar study in Bosnia and Herzegovina has shown that the morbidity rate ranged from $3.83 / 100,000$ inhabitants in 2004 to 33.4/100 000 inhabitants in 2008 and showed an increase between the examined period from 2001 to 2008 [10]. In Serbia, a country with a moderate incidence of human brucellosis, the morbidity rate was $0.15 / 100,000$ inhabitants in 2006 and the maximum incidence amounted to $3.3 / 100,000$ inhabitants in 1991, Kosovo and Metohija 12/100,000 (in the analyzed period 1980-2008) [11]. In Albania the reported incidence of human brucellosis in 2008 was 25/100,000 inhabitants [12] and in Greece, it was 2.2/100,000 inhabitants in 2003 [13]. In the European Union, the incidence ranged from 0.17 to $0.2 / 100,000$ of population in the period 2005-2006 [14]. This shows that at the Balkan Peninsula, Republic of Macedonia is a country with high incidence of human brucellosis.

With the development of the trend of human brucellosis, we found that the disease has been decreasing for the analyzed period (1999-2009). This is probably due to the long effort to educate the general population, in terms of changing their habits to consume pasteurized milk and dairy products, and other preventive measures and activities of relevant institutions to raise public awareness.

When analyzing the epidemiological features of human brucellosis in our country for the period from 1999-2009, there were 2,872 (69\%) males and 1,295 $(31 \%)$ female carriers, where men were statistically significantly prevailing over women ( $p=0.00001)$. Studies in Bosnia and Herzegovina and Serbia have shown almost the same results $[10,11]$. This is due to the increased professional risk of male's population, i.e., men are engaged in activities where there is a close contact between man-like animal herder/farmer (sheep and goats), butcher, merchant goods and the risk of brucellosis transmission from animal to human is significantly greater.

The registered cases of human brucellosis by age were grouped into age groups of $0-9,10-19,20$ 29, 30-39, 40-49, 50-59, and 60 and over. The analysis showed that brucellosis affected all ages, but the disease was significantly more common in the elderly in the age group over 60 years, $17.85 \%$ of the total number of registered cases $(\mathrm{t}=3.721 ; \mathrm{p}=$ $0.0137)$. The lowest percentage of patients - $6.86 \%$ (286 cases) was registered among children in the age group 0 to 9 years. This age group was treated separately, and the analysis showed that the frequency of the disease grows with the increasing of the age $(r=0.96)$, similar to the results presented in other Balkan countries [10,11].

Distribution of human brucellosis by age groups is important because it can affect the clinical picture including frequency and type of signs, symptoms and complications [15]

Brucellosis in humans is a typical seasonal disease with maximum cases found in spring and 
summer and minimum in fall-winter period. The number of infected persons is growing progressively from January to May, reaching its maximum in June and July and then it declines. Most of the registered human brucellosis in the analyzed period (1999-2009) was recorded in June (672 patients), while the smallest number was registered in December (96 patients). In Serbia human brucellosis is also a seasonal disease with most cases found in September, in the analyzed period (1994-2008) [11], and in Bosnia and Herzegovina in April, for the period from 2001-2008 [10].

This is due to the fact that late winter and early spring is the period of mating of sheep and goats, and the affected animals often have fetal abortion (lochias are the most infective). Farmers in that period are at highest risk of infection with brucellosis via contact (direct and indirect) and air the breath/inhalation of the agent. Secondly, an additional cause of occurrence of the disease in this period is the fact that spring is the time when fall religious holidays and Eid al-Adha and thus demand for lambs and sheep is greater (this in turn is associated with higher uncontrolled circulation of animal and custom-religious slaughter). In June and July, the risk of infection with brucellosis is also increased due to climate conditions and way of breeding sheep and goats (increased migration of flocks, movement and trade of animals).

\section{Recommendations}

In order to achieve lower rates of incidence and prevalence of human and animal brucellosis and its eventual eradication it is necessary to establish a multidisciplinary approach and multisectoral cooperation of all relevant institutions in the field of public health and veterinary health at all levels.

The competent institutions have to increase efforts by promotion, education and other public health actions and methods of prevention, education and raising public awareness of the general population and vulnerable groups (farmers, butchers and other related professions) to protect against brucellosis.

The program for investigating the incidence, prevention and eradication of brucellosis in the population in the country, which is carried out by the Government of the Republic of Macedonia on an annual basis has, to proceed to adopt, implement and to upgrade and supplement in accordance with the latest scientific achievements in the field of epidemiology, public health and other related disciplines.

Continuous surveillance of human and animal brucellosis by developing and monitoring programs is indispensable.

Safe operation with mandatory use of proper protective equipment has to be encouraged at the workplace. The high-risk groups should educate continuously to recognize clinical signs and symptoms of the disease for timely diagnosis and treatment.

Food service operators should effectively apply the system for Hazard Analysis and Critical Control Points (HACCP) in the production of food (especially milk and dairy products) by the food operators.

\section{References}

1. Dames S, Tonnerre C, Saint S, Jones SR. Don't know much about history. N Engl J Med. 2005; 352:2338-2342.

2. Zaharija, I. Zarazne bolesti domaćih životinja. Zagreb: Školska knjiga, 1978; 561-575.

3. Institute for Public Health of the Republic of Macedonia http://www.iph.mk/index.php?option=com content\&view=article\&id= 138\%3A2008-2009\&catid=41\%3Afrontcategory\&lang=en Accessed: April 30, 2010

4. Karadzinska-Bislimovska J, Minov J, Mijakoski D, Stoleski S, Todorov S. Brucellosis as an Occupational Disease in the Republic of Macedonia. Maced J Med Sci. 2010; 3(3):251-256

5. Taleski V, Zerva L, Kantardjiev T, Cvetnic Z, Erski-Biljic M, Nikolovski B, et al. An overview of the epidemiology and epizootology of brucellosis in selected countries of Central and Southeast Europe. Vet Microbiol. 2002; 90:147-155

6. Kirandziski T, Nikolovska G, Nakova E, Smilenovska B Strojmanovska B, Naletoski I, et al. Brucellosis control in small ruminants in the Republic of Macedonia. Prilozi. 2010; 31(1):181 190.

7. Donev D, Karadzovski Z, Kasapinov B, Lazarevik V Epidemiological and public health aspects of brucellosis in the Republic of Macedonia. Prilozi. 2010; 31(1):33-54

8. Nikolovski B, Karadzovski Z, Kostovska J. 30 Years of Brucellosis in the Republic of Macedonia: Experience with its Prevalence, Prevention and Control. Maced J Med Sci. 2010; 3(3):263-267.

9. Kisman M, Donev D, Kisman A. International Standards and Strategies for the Surveillance, Prevention and Control of Brucellosis. Maced J Med Sci. 2010; 3(3):273-277.

10. Zarema Obradović, Ramiz Velić. Epidemiological Characteristics of Brucellosis in Federation of Bosnia and Herzegovina. Croat Med J. 2010; 51: 345-350.

11. Radovan Čekanac, Jovan Mladenović, Elizabeta Ristanović, Srđan Lazić. Epidemiological Characteristics of Brucellosis in Serbia, 1980-2008. Croat Med J. 2010; 51: 337-344.

12. Mersinaj K, Bino S, Crilly J. A review of brucellosis control in Albania. Book of abstracts of MetaNET Project Thematic Scientific Conference. Brucelossis in SEE and Mediterranean Region. Struga: Republic of Macedonia, 2009.

13. Jelastopulu E, Bikas C, Petropoulos C, Leotsinidis M. Incidence of human brucellosis in a rural area in Western Greece after the implementation of a vaccination programme against animal brucellosis. BMC Public Health. 2008; 8:241-246.

14. The Community Summary Report on Trends and Sources of Zoonoses, Zoonotic Agents and food-borne outbreaks in the European Union in 2008. The EFSA Journal. 2010; 1496.

15. Bosilkovski M, Krteva Lj, Dimzova M, Vidinic I, Sopova Z, Spasovska K. Human Brucellosis in Macedonia - 10 Years of Clinical Experience in Endemic Region. Croat Med J. 2010; 51: 327-336 